\title{
GIS-SWIAS: Tool to Summarize Seawater Intrusion Status and Vulnerability at Aquifer Scale
}

\author{
Leticia Baena-Ruiz (i) and David Pulido-Velazquez (i) \\ Department of Research on Geological Resources, Geological Survey of Spain (IGME), Urb. Alcázar del Genil, 4-Edif. Bajo, \\ Granada 18006, Spain
}

Correspondence should be addressed to Leticia Baena-Ruiz; 1.baena@igme.es

Received 13 March 2020; Accepted 26 April 2021; Published 12 May 2021

Academic Editor: Emiliano Tramontana

Copyright (c) 2021 Leticia Baena-Ruiz and David Pulido-Velazquez. This is an open access article distributed under the Creative Commons Attribution License, which permits unrestricted use, distribution, and reproduction in any medium, provided the original work is properly cited.

\begin{abstract}
In this paper, we introduce GIS-SWIAS, a novel generalized ArcGIS ArcToolbox that helps to analyze seawater intrusion (SWI) status and vulnerability at aquifer scale (SWIAS). It is a user-friendly tool that can be applied to any aquifer and is fully integrated in the ArcGIS environment, which is a widely available software tool. It is the first ArcGIS tool with these characteristics focusing on SWI analyses that we can find in the literature. GIS-SWIAS is able to deal with georeferenced information; it is easy to introduce the required data (inputs) and to efficiently perform the demanding computational operations required. Its outputs are in the form of shapes, reports, and images (maps, conceptual cross sections, and time series of lumped indices) to summarize the magnitude, intensity, and temporal evolution of SWI within an aquifer for specific dates or by showing statistics for a chosen time period. It can be applied to assess historical SWI dynamic in cases where there is no groundwater flow model. In those cases, the spatial distribution is assessed by applying simple interpolation techniques. Nevertheless, if we want a rational quantitative analysis of the sustainability of alternative management scenarios to the SWI problem, the GIS-SWIAS tool requires that information on hydraulic head and chloride concentration distribution is generated from simulations of their impacts by a calibrated density-dependent flow model. In such cases, adaptation strategies to potential future scenarios-whose distributed impacts have to be propagated within the previously calibrated models-could usefully be analyzed and compared using this tool. Given all these ways that the GIS-SWIAS tool can be applied, it provides a valuable tool for both the researcher and technician to assess SWI dynamics and aquifer resilience under different scenarios. It can support the decision-making process by helping to make a rational selection of sustainable management strategies. Its performance for the analyses of historical and potential future scenarios has been tested and confirmed in two case studies described in previous research works.
\end{abstract}

\section{Introduction}

Seawater intrusion (SWI) in coastal aquifers is a worldwide problem affecting groundwater-dependent ecosystems and human health. In recent decades, society's awareness of this issue has grown and this has been reflected in the legal framework of many countries. For example, the European Union's Water Framework Directive (WFD) requires that river basin plans address the achievement of a good qualitative and quantitative status of groundwater bodies [1]. In coastal groundwater bodies, intrusion is one of the main issues that need to be considered to achieve or maintain good groundwater status.
The impacts of SWI on groundwater have a heterogeneous distribution. Analyses of spatiotemporal distribution of SWI require salinity or chloride concentration to be mapped for different dates. Depending on the issue to be addressed and the available information, SWI can be approximated using various models. SWI can be mapped either by applying simple interpolation models $[2,3]$ to existing point data or by simulating the physical processes using transient density-dependent groundwater flow models $[4,5]$. The results obtained with these physical process models can be applied to assess sustainable management strategies, i.e., strategies that prevent deterioration of the aquifer resource due to SWI [6]. They can even be employed 
to propagate impacts of potential local climate change (CC) [7] or global change (GC) scenarios and to identify adaptation strategies [8].

Based on the salinity or chloride concentration maps at different dates, some authors have defined indices to summarize SWI [9-12]. These indices provide an overview of the intensity and spatial distribution or percentage SWI at aquifer scale. Such indices need to offer descriptive and synthetic results so that the status of SWI in different aquifers and over different periods can be compared. These index-methods $[9,13]$ establish threshold values for chloride to define the basis of SWI that have been defined in various ways: by referencing natural background levels and/or by taking into account the concentrations required to protect dependent ecosystems or human health [14].

When simple interpolation is used to draw the maps used to define the indices, analyses must be limited to the historical period for which there are data. In contrast, physical process models can be applied to propagate various potential conditions and so maps can be obtained for different scenarios (e.g., alternative management scenarios or future potential CC scenarios); in this latter case, the output can be used to determine the optimum strategy and therefore support the decision-making process [15].

In addition to the SWI status and dynamics, another important issue to take into account in identifying sustainable management strategies for coastal aquifers is the aquifer's vulnerability to SWI. In the literature we found various methods for mapping SWI vulnerability, such as the GALDIT method [16]. Then, by applying a method to express vulnerability as an index, we can also get an overview of the intensity and spatial distribution or percentage of SWI at aquifer scale [13].

\section{Related Works}

In the literature we find many tools to assess and analyze water resource problems [17-19]. The success of these software tools lies in their usability. A user-friendly environment and the implementation in commonly used software are key factors for their success and popular use. For example, groundwater studies usually employ Geographic Information Systems (GIS) since they are powerful, widely available tools that can deal with large amounts of spatial georeferenced information [20] and make calculations in an efficient way to provide quick results [21]. The analysis and mapping of hydrogeological data provide useful spatiotemporal information to decision makers [22].

GIS tools have been widely used for different purposes related to groundwater issues [23, 24]. Several authors have developed different source codes within GIS environment (Alcaraz et al. [25]; Bhatt et al. [26]) for hydrogeological modelling. A free and open source module included in FREEWAT was developed by Criollo et al. [19] to analyze hydrochemical and hydrogeological data in order to simplify the characterization of the groundwater bodies at chemical risk. Almeida et al. [27] coupled a groundwater flow model into a GIS environment to simulate transient flow in a confined aquifer. Akbar et al. [28] and Ríos et al. [29] presented GIS-based models to simulate contaminants leaching into groundwater.

In coastal areas, a three-dimensional GIS-based groundwater flow model was developed [30] to simulate the aquifer's response to past climate changes. A new ArcGIS tool for groundwater flow simulation and visualization of results was also implemented by [19]. Other authors (De Filippis et al. [31]) applied a previously developed GIS-based tool (AkvaGIS), in addition to a groundwater flow model, to study the impacts of pumping on seawater intrusion in coastal aquifers in Malta and Italy. This tool was used in other studies (Perdikaki et al. [32]) to analyze hydrochemical parameters in a coastal aquifer that presented seawater intrusion problems.

Nevertheless, as far as we know, there is no ArcGIS tool focusing on analyzing seawater intrusion (SWI) status and vulnerability at aquifer scale.

In this paper, we describe the development of a new ArcGIS tool called GIS-SWIAS, which is the implementation of the index-based method for assessing aquifer status and vulnerability to SWI proposed by $[13,15]$. It helps to analyze SWI status and/or vulnerability at aquifer scale using a mixed lumped-distributed analysis. It is a user-friendly ArcGIS ${ }^{\circledR}$ toolbox that performs all the required calculations for specific dates or temporal periods inside a GIS environment. The data inputs to the model are hydraulic head and chloride concentration maps. The tool provides two options to map these variables: the first is to use point data by applying interpolation techniques integrated within GIS-SWIAS, while the second is to take these data from existing external distributed models. The second approach allows different climatic and/or management scenarios to be assessed and compared. From those maps, extensive calculations have been fully automatized in GIS-SWIAS to display the results as distributed maps of affected and nonaffected volumes (at a specific moment or over a period of time), mean conceptual cross sections, and a lumped index ( $\mathrm{Ma}$ and L_Vul) to analyze the global intensity and the dynamics of SWI.

Although there are many GIS-based tools in the literature that allow simulating groundwater flow and analyzing groundwater quality, none of them perform spatial and temporal analysis on groundwater quality and vulnerability issues. Moreover, this new tool provides simple pictures that summarize the proportional affected area within the aquifer according to a chloride threshold. For this purpose, GISSWIAS has been applied to analyze the seawater intrusion problem, but this tool could be applied to represent the global status of an aquifer to any contaminant. The main objective of GIS-SWIAS is to provide an easy-to-use tool through a userfriendly interface that can be used by users at different levels of expertise to summarize the SWI problem at aquifer scale. It allows analyzing long time periods with a low computing cost.

\section{Description of GIS-SWIAS Tool: Models, Inputs, and Outputs}

GIS-SWIAS is an ArcGIS ArcToolbox that contains the models required to analyze SWI status and vulnerability at aquifer scale, according to the methodology described in 
previous works $[13,15]$. Figure 1 shows the structure of the tool, which includes inputs, steps, and models, as well as the outputs generated.

To determine the overall status of the aquifer, the inputs to the tool include variables (to characterize the historical evolution of hydraulic head and chloride concentration) and parameters (to define aquifer geometry and hydrodynamic behaviour). Data describing the historical evolution can come from direct observations (monitoring network) or other techniques (geophysical applications, etc.). For the vulnerability assessment, an additional input is required: a distributed vulnerability index map, which comes from other intrinsic information (aquifer type, conductivity, distance from the shoreline, and bicarbonate concentration).

The results/outputs produced to summarize status and vulnerability to SWI through visual displays and time series are as follows: (1) maps of aquifer volumes affected by SWI; (2) 2D conceptual cross sections (with mean penetration inland and mean thickness on specific dates, or mean values over a period of time); (3) lumped index (mass of chloride that causes the concentration in some areas to exceed the SWI threshold and lumped vulnerability index) to summarize the global dynamic of SWI within the aquifer.

\subsection{Description of the Outputs: Theoretical Background.} In order to assess the maps of SWI-affected aquifer volumes for different dates, we need to compile (A) maps of chloride concentration or vulnerability to SWI; (B) maps of groundwater volumes for specific dates; (C) threshold of chloride concentration or vulnerability that will be used to tag which parts of the aquifer are impacted (areas with chloride concentration or vulnerability index exceeding the threshold). The tool provides two options with respect to the input maps (A) (chloride or vulnerability maps) and (B), either calculating the maps internally from point data by applying interpolation techniques integrated within GISSWIAS or taking the maps from existing external distributed models; the second option means that various potential climatic and/or management scenarios can be compared and assessed. Maps of groundwater volume are calculated by combining hydraulic head, geometry, and the storage coefficient. The maps of groundwater volume and chloride concentration are combined to assess the aquifer volume affected by using a chloride threshold $\left(V_{r}\right)$. This threshold is assumed to be equal to the natural background level of the aquifer, or the reference quality standard determined by authorities in order to maintain a good groundwater status. The affected volume is defined as the groundwater volume of resource whose chloride concentration is above the established threshold.

2D conceptual cross section depicts the magnitude of the intrusion process in the aquifer at a specific moment, or the mean values in a period of time. The cross section is defined orthogonal to the shoreline. It summarizes the mean geometry of the affected volume, i.e., the mean thickness and inland penetration of the aquifer volume with chloride concentration above the threshold. The average affected thickness $T_{h a}(m)$ and inland penetration $P(m)$ of the intrusion can be calculated by summing the values in each cell $i$ of the aquifer mesh where the chloride concentration exceeds the threshold:

$$
\begin{aligned}
T_{h a}(m) & =\frac{\sum V_{i\left(>V_{r}\right)}}{\sum S_{i\left(>V_{r}\right)}}, \\
P(m) & =\frac{\sum V_{i\left(>V_{r}\right)},}{T_{h a} * L_{\text {coast }}} \\
V_{i\left(>V_{r}\right)}\left(m^{3}\right) & =S_{i}\left(m^{2}\right) * b_{i}(m) * \alpha_{i},
\end{aligned}
$$

where $V_{\mathrm{i}(>\mathrm{Vr})}$ is the groundwater volume $\left(\mathrm{m}^{3}\right)$ in the cell $i$ with a chloride concentration (or vulnerability) exceeding $V_{\mathrm{r}} ; S_{\mathrm{i}}$ is the surface area $\left(\mathrm{m}^{2}\right)$ of the cell $i$ with chloride concentration (or vulnerability) exceeding $V_{\mathrm{r}} ; b_{\mathrm{i}}$ is the saturated thickness $(m)$ within the cell $i$ with $\mathrm{Cl}$ concentration (or vulnerability) above $V_{\mathrm{r}} ; \alpha_{\mathrm{i}}$ is the storage coefficient in the cell $\mathrm{i}$; $\mathrm{L}_{\text {coast }}$ is the length of coastline $(\mathrm{m})$.

The mean chloride concentration (C) of the affected volume is

$$
C\left(\frac{m g}{l}\right)=\frac{\sum\left(C_{i\left(>V_{r}\right)} * V_{i\left(>V_{r}\right)}\right)}{V_{\left(>V_{r}\right)}},
$$

where $C_{i\left(>V_{r}\right)}$ is the chloride concentration $(\mathrm{mg} / \mathrm{l})$ in cell $i$; $V_{i(>V r)}$ is the groundwater volumes $\left(\mathrm{m}^{3}\right)$ in cell $i$ with a concentration exceeding $V_{r} ; V_{\left(>V_{r}\right)}$ is the total groundwater volume $\left(\mathrm{m}^{3}\right)$ of the affected area.

The increment of chloride concentration (IC) above the threshold $\left(V_{r}\right)$ in the affected volume is

$$
\operatorname{IC}\left(\frac{m g}{l}\right)=C-V_{r} \text {. }
$$

Both variables, the conceptual cross section and IC index, give an overview of the magnitude and intensity of the intrusion process per linear metre of coast at a specific moment in time.

The lumped index $\mathrm{Ma}$ (mass of chloride that causes the concentration in some areas to exceed the threshold) to summarize the global dynamic of SWI within the aquifer is obtained multiplying the increment of concentration (IC) by penetration $(P)$ and affected thickness $\left(T_{h a}\right)$ from (1) and (3).

$$
M a\left(\frac{k g}{m}\right)=P(m) * I C\left(\frac{m g}{l}\right) * 10^{-3} * T_{h a}(m) .
$$

The vulnerability to SWI (or vulnerability to contamination in general) is assessed and summarized following the same steps to assess the SWI status. In this case, instead of chloride concentration values, a distributed map of groundwater vulnerability has to be generated by applying any index-based method (e.g., GALDIT) and the threshold applied to identify the affected area is defined by a specific vulnerability class (e.g., high or very high vulnerability).

The affected volume corresponds to the groundwater that presents vulnerability values above the threshold (e.g., very high vulnerability). The average affected thickness 


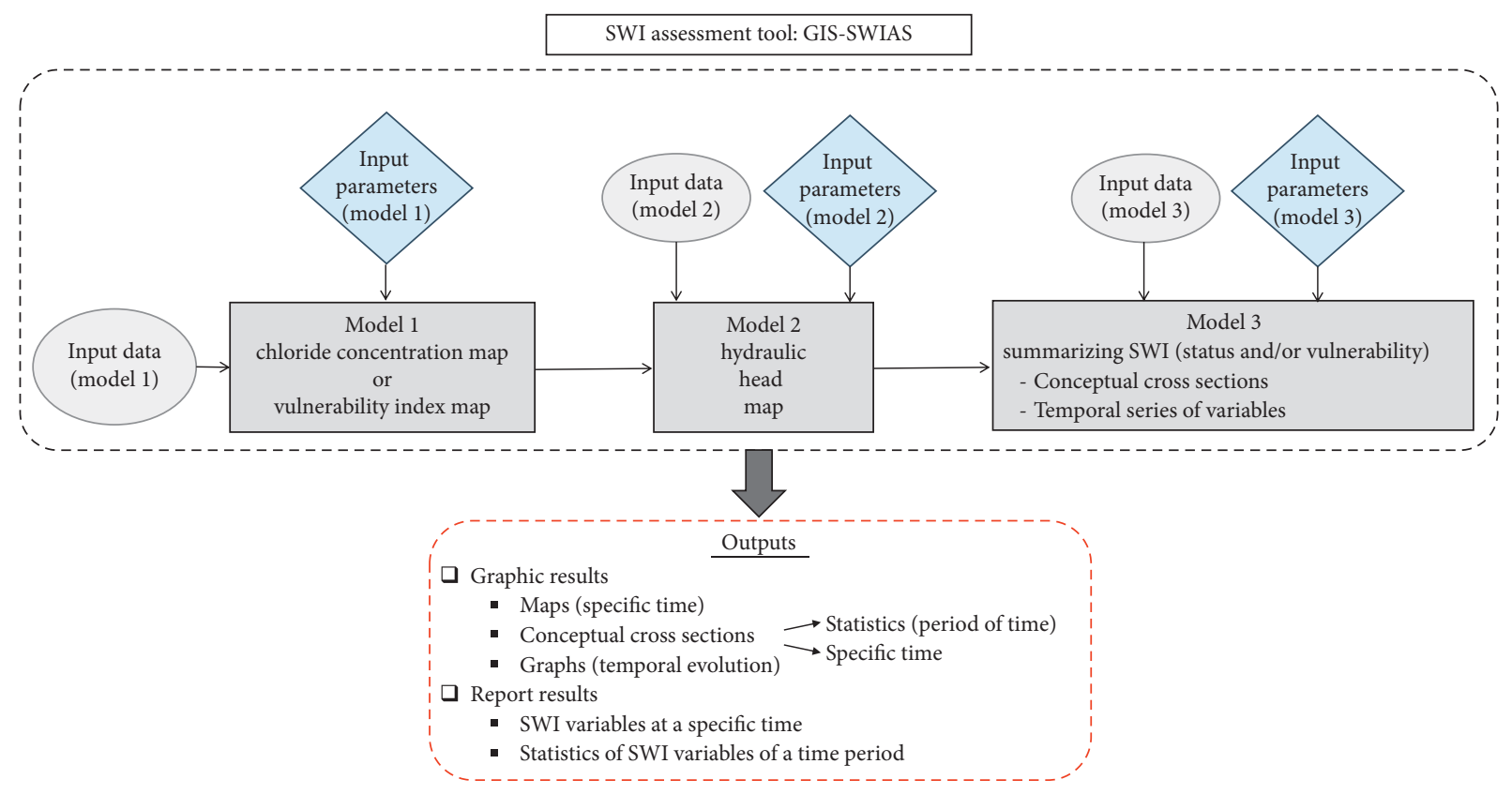

FIgURE 1: Workflow of the GIS-SWIAS ArcToolbox.

$\mathrm{T}_{\text {ha }}(\mathrm{m})$ and inland penetration $\mathrm{P}(\mathrm{m})$ are calculated by applying (1).

The lumped index to assess vulnerability is

$$
L_{-} \operatorname{Vul}(-) \frac{\sum\left(\operatorname{Vul}_{i\left(>V_{r}\right)}\right) * V_{i\left(>V_{r}\right)}}{V_{\left(>V_{r}\right)}}
$$

where $\operatorname{Vul}_{i\left(>V_{r}\right)}$ is the value of the vulnerability index (-) in cell $i$.

The concept of Ma and L_Vul involves some simplifications, in accordance with the definition of the conceptual cross sections. While 2D maps and cross sections summarize the extent and magnitude of SWI and vulnerability in an aquifer at a specific time, $\mathrm{Ma}$ and $\mathrm{L}_{-} \mathrm{Vul}$ indices show the lumped intensity and temporal dynamic of the SWI and vulnerability to SWI at aquifer scale.

3.2. Tool Programming in ArcGIS. GIS-SWIAS is an ArcGIS ArcToolbox composed of a chain of models programmed in ModelBuilder. ModelBuilder is a visual programming language that allows chaining and sequencing several geoprocessing ArcGIS tools through a user-friendly interface. ModelBuilder is available within the tool bar in ArcGIS. It allows the addition of any geoprocessing tool of ArcGIS by linking and providing its output and transferring it to another tool as input.

Programming in ModelBuilder allows us to automate a workflow to create a model, which can be documented and shared as a ArcGIS tool. ModelBuilder contains a script tool to link with Python scripts and other models. It also allows iteration of a workflow, so it can be very useful to analyze the evolution of the historical hydrogeological processes.

The three models that compose GIS-SWIAS have been compiled by adding different tools from ArcToolbox to create shapes from point data, to interpolate, etc. Figure 2 shows the workflow of one of the three models.

Although ModelBuilder is an intuitive and easy-to-use tool, the integration of lots of geoprocesses in the same model may be difficult. Because several geoprocesses have dynamic parameters and the user interaction is necessary, GIS-SWIAS was divided into three steps (models) that have to be executed following the workflow shown in Figure 1.

3.3. Description of the Models within GIS-SWIAS. GIS-SWIAS contains three ModelBuilder models (Figure 2) that can be applied individually or used sequentially to produce a complete lumped assessment of the SWI at aquifer scale. GIS-SWIAS can be shared with other users and it can be added as a toolbox as shown in Figure 3. The run sequence follows the order shown in the workflow (Figure 1): "Chloride concentration map", "Hydraulic head map," and "Summarizing SWI". These models can be run within the ArcToolbox window providing a user-friendly graphical user interface.

3.3.1. "Chloride Concentration map" Model. The "Chloride concentration map" model generates a classified chloride concentration shapefile from a point feature table in text format by using Inverse Distance Weighting (IDW) interpolation technique (other interpolation techniques could be implemented in this tool). It can also import chloride concentration fields from Visual MODFLOW files. The dialog box shown in Figure 4 is opened by double-clicking the model tool on the ArcToolbox window.

The model requires a polygon shapefile of the aquifer and the workspace containing a text file for each date to be analyzed. The text files have to include $X$ and Y UTM coordinates that define the locations of the point features 


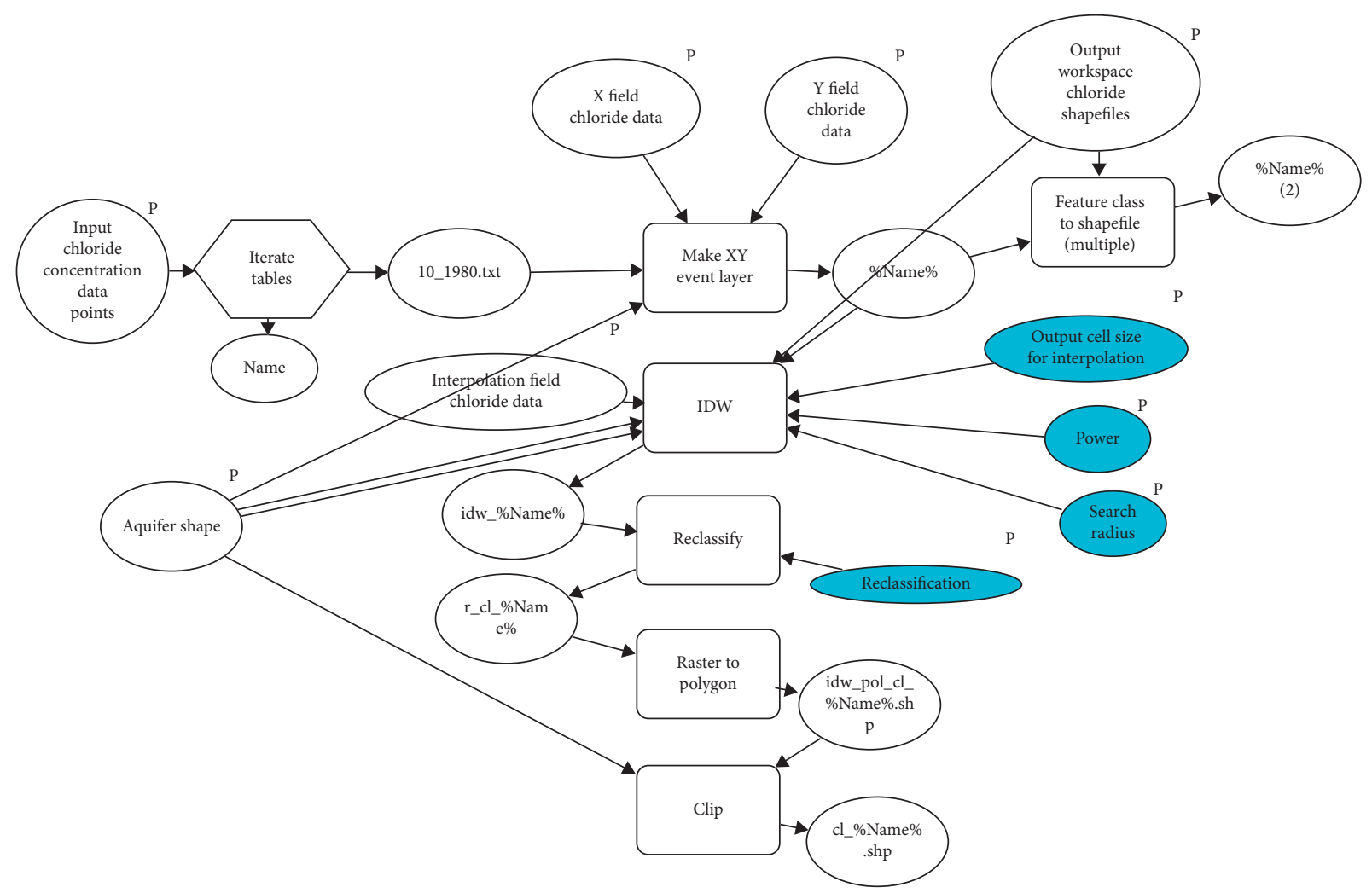

Figure 2: Workflow of "Chloride concentration map" model.

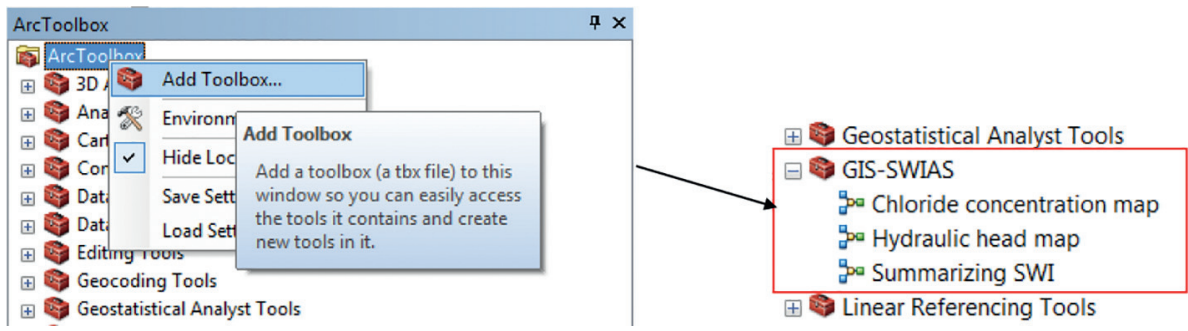

Figure 3: GIS-SWIAS in the ArcToolbox.

and chloride concentration values $(\mathrm{mg} / \mathrm{l})$ in the observation wells. Text files also have to include column header, as shown in Figure 4 . The text filename cannot exceed eight characters nor include blank spaces or special characters (underscore can be used as a substitute). It is not necessary that all points contain data every date of the period to be analyzed.

The user has to indicate the fields (columns) in the input table that contain the $X$ and $Y$ coordinates and the chloride concentration value for each point (Figure 5). Optional settings concerning IDW interpolation techniques can be changed by the user. A reclassification of the values after interpolation is also required. Finally, the user has to choose a folder where the output shapefiles will be saved.

When all the required parameters are filled out, the model can be executed by clicking "OK" at the bottom of the dialog box. The execution screen (Figure 6) shows the running processes and it can be closed when the execution has successfully completed.
The "Chloride concentration map" model provides the following shapefiles for each date analyzed: (1) point shapefile of chloride concentration data; (2) raster from data interpolation; (3) polygon shapefile from interpolation covering the default extension; and (4) polygon shapefile from interpolation clipped to the shape of the aquifer.

3.3.2. "Hydraulic Head Map" Model. The "Hydraulic head map" model generates a classified hydraulic head shapefile from a point feature table in text format. It also generates a shapefile containing aquifer variables (chloride concentration and hydraulic head values) and aquifer parameters (storage coefficient and bottom of the aquifer). The dialog box is shown in Figure 7.

This model has the same input requirements as for the "Chloride concentration map" model but focuses on hydraulic head data (m.a.s.l.). It also allows hydraulic head fields to be imported from Visual MODFLOW. The name of 


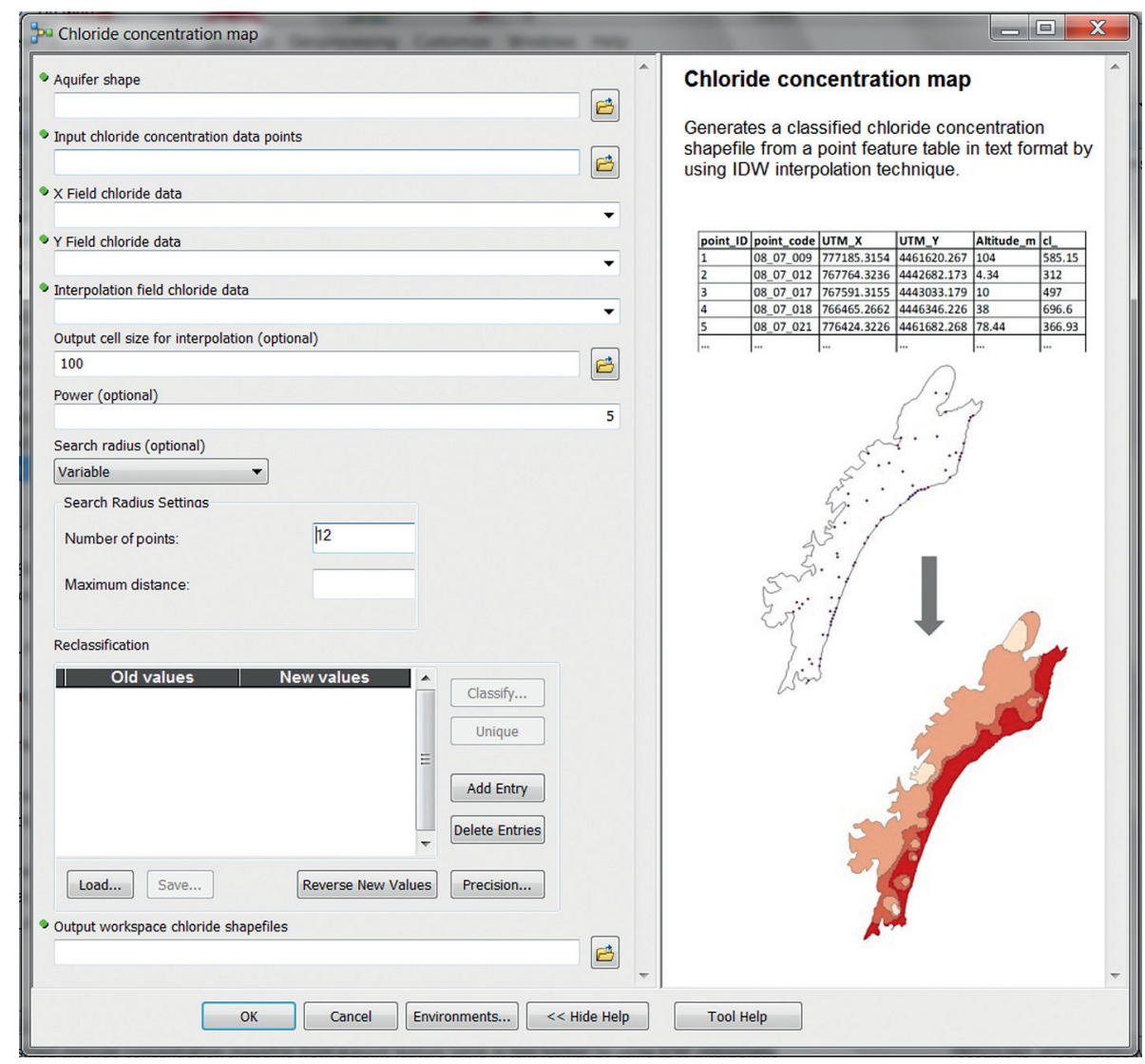

Figure 4: Dialog box of the "Chloride concentration map" model.

hydraulic head text files must be the same as the chloride concentration text files for each time period analyzed.

The user has to indicate the location of the chloride shapefiles generated in the previous model ("Chloride concentration map" model). It also requires polygon shapefiles of storage coefficient and bottom $(m)$ of the aquifer as inputs.

The model generates shapefiles of hydraulic head data in an analogous way to the "Chloride concentration map" model. Moreover, it provides a polygon shapefile containing variables for each date analyzed (chloride concentration and hydraulic head values) and parameters (bottom and storage coefficient) of the aquifer. This shapefile is named "union_\% name of the hydraulic head text file\%_hh.shp", where "\% name of the hydraulic head text file $\%$ " is variable if different dates are analyzed.

3.3.3. "Summarizing SWI" Model. For the "Summarizing SWI" model, the methodology proposed in Baena-Ruiz et al. [13,15] and described in Section 3.1 has been implemented in the ArcGis environment. This tool generates Excel ${ }^{\circledR}$ tables containing statistics that summarize SWI at aquifer scale. It also generates conceptual cross sections (.shp), where the mean affected and nonaffected volumes are drawn for the aquifer (average values over a time period or instantaneous values on a specific date). If different dates are analyzed, it shows graphs representing the temporal evolution of $\mathrm{Pa}$ and Ta variables, percentage of affected volume, chloride concentration within the aquifer, and Ma index (or lumped vulnerability index). The dialog box for global status assessment is shown in Figure 8.

The "Summarizing SWI" model requires the folder path where the results of the "Hydraulic head model" have been previously saved to be specified. In this folder, the shapefile named "union_\%name of the hydraulic head text file $\%$ _hh.shp" contains chloride concentration, hydraulic head, bottom of the aquifer, and storage coefficient fields. The user has to select from the pull-down list the corresponding column in the input shapefile for each field, as shown in Figure 9.

The next required parameter in this tool is the "Chloride threshold." It is defined as the chloride concentration value above which the aquifer is considered to be affected by SWI. This threshold may be set as the natural background level of the aquifer or as the relevant environmental quality standards. Hinsby et al. [14] proposed a method to calculate groundwater thresholds values based on these criteria.

The shoreline length $(m)$ is also required for subsequent calculations.

$X$ and $Y$ axes establish the coordinate system of the conceptual cross sections. The GIS-SWIAS tool provides polyline shapefiles for $X$ and $Y$ axes located at $(0,0)$, but the user can translate them to another coordinate origin or create new ones. 


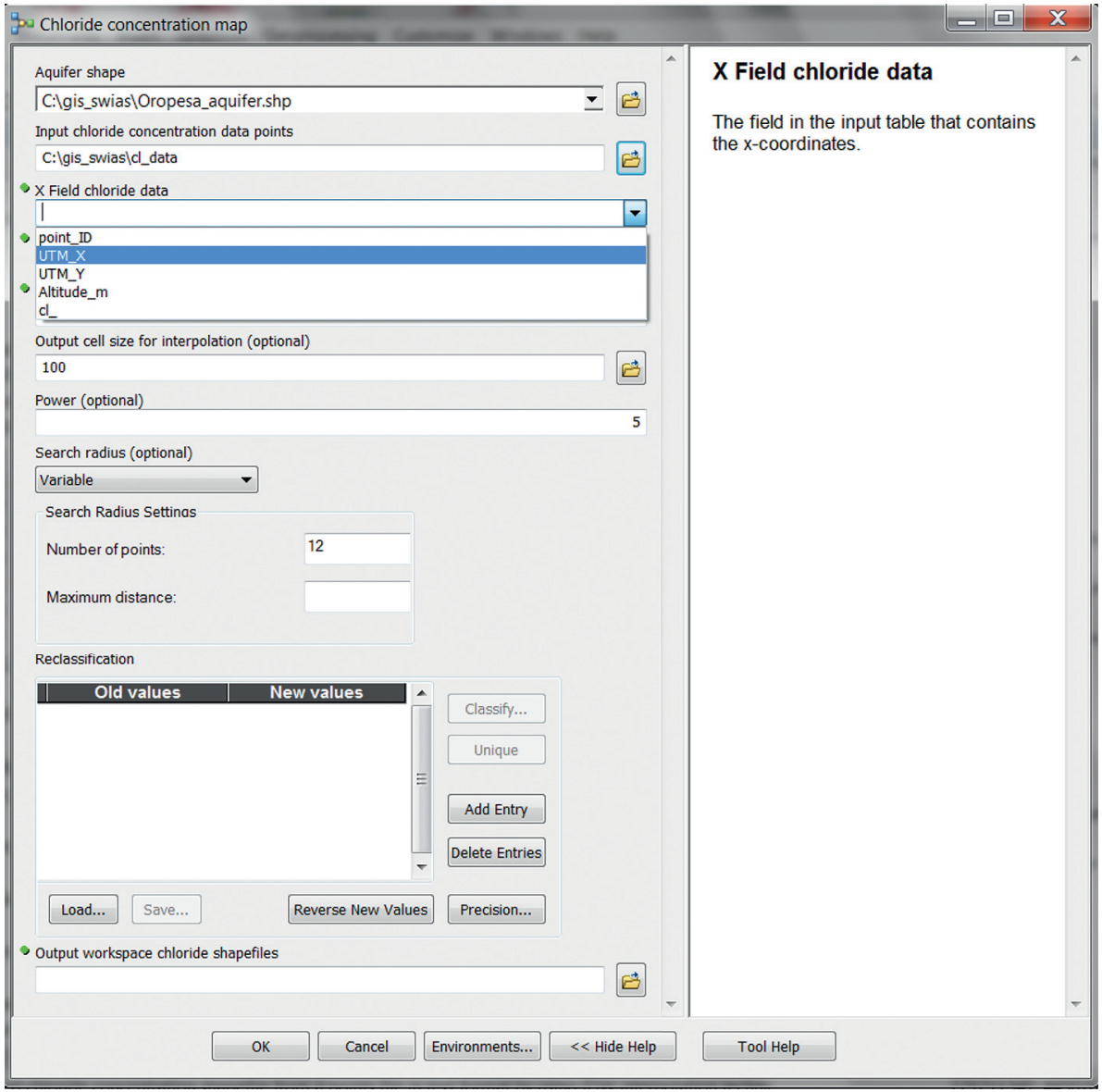

FIGURE 5: Setting options defined by the user.

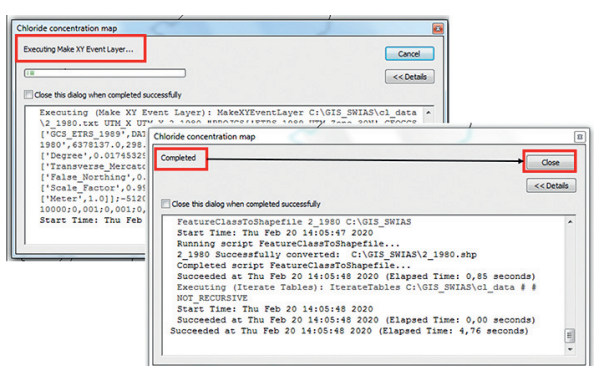

Figure 6: Execution screen of the model.

The vertical scale factor is used to rescale the vertical magnitude (Ta) of the conceptual cross section if the factor $\mathrm{Ta} / \mathrm{Pa}$ is too small. If vertical scale factor $=1$, the conceptual cross section will maintain the real size ratio.

Finally, two paths where the output results will be saved are required. "Output workspace statistic" will contain lumped variables reports in Excel table format for each date analyzed (Figure 10) and mean statistics for the entire period. Four graphs will be also saved in this path: (1) temporal evolution of $\mathrm{Pa}$ and $\mathrm{Ta}$ variables; (2) percentage volume affected; (3) Ma index; and (4) chloride concentration within the aquifer (mean chloride concentration in the aquifer, mean chloride concentration in the affected volume, and the increment of concentration within the affected volume above the threshold).

"Output workspace results" will contain the polygon shapefiles that allow the (1) mean affected and (2) nonaffected conceptual cross section within the aquifer for each date analyzed to be drawn, (3) the mean affected and (4) nonaffected conceptual cross section within a time period, and the (5) maximum affected cross section for a time period. These two paths can be the same for all results, but they have to be different from the output paths of the previous models.

Figure 11 and Table 1 show the graphical and statistical summaries, respectively, from the GIS-SWIAS tool.

The GIS-SWIAS tool can provide results for each date where information is available; these are obtained by iterative application of the described method. GIS-SWIAS allows historical [13] and future periods [15] to be analyzed if the hydraulic head and chloride maps come from a densitydependent flow model. By this means, GIS-SWIAS can be used to analyze adaptation strategies [15] in terms of reducing SWI, taking into account future potential scenarios that might include $\mathrm{CC}$ and/or GC, also considering projected land use change scenarios (new urbanized areas, crop transformations) [15].

Moreover, this tool may be also used to summarize SWI vulnerability, for any index method applied to assess it. In 


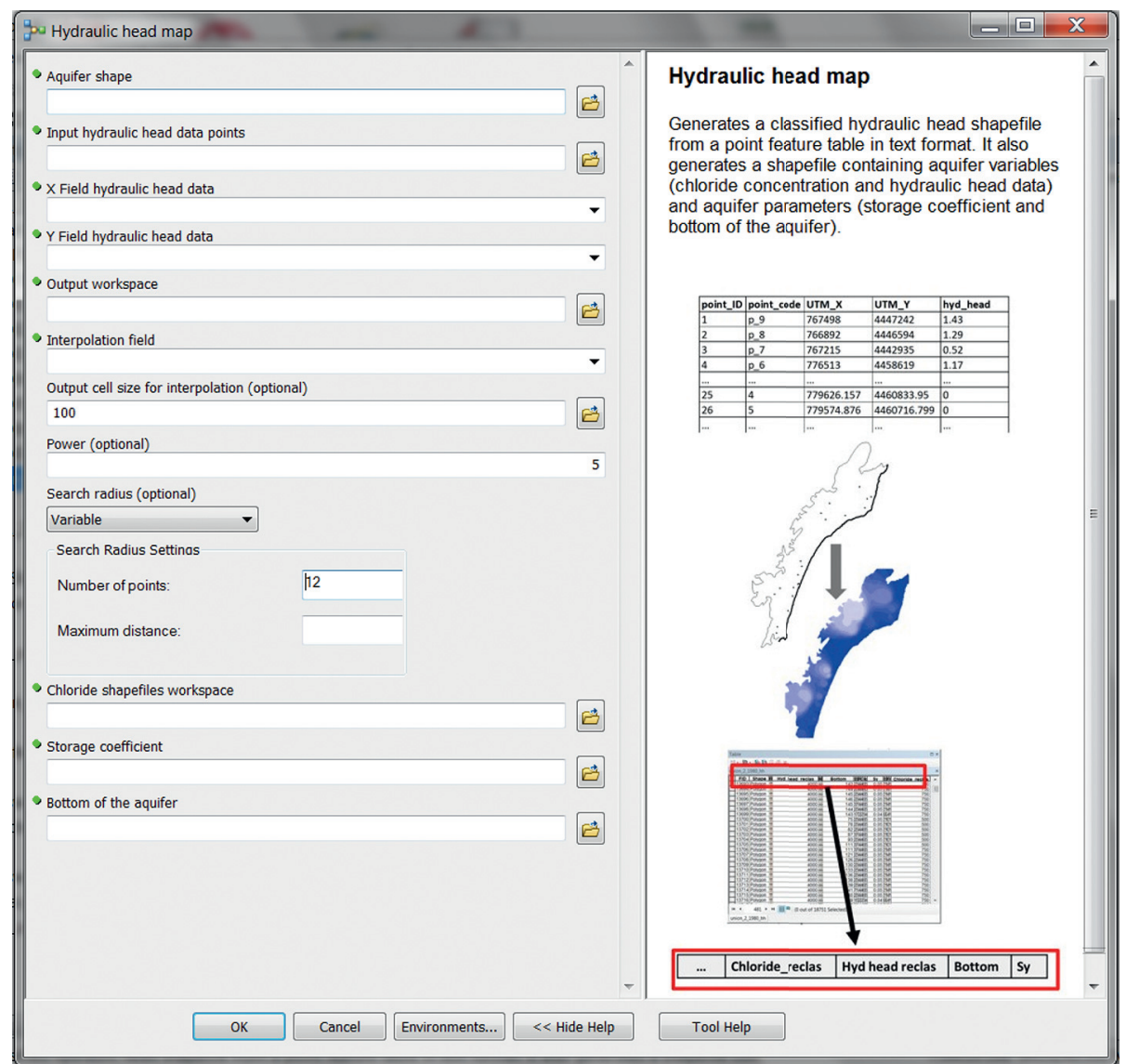

FIgURE 7: Dialog box of the "Hydraulic head map" model.

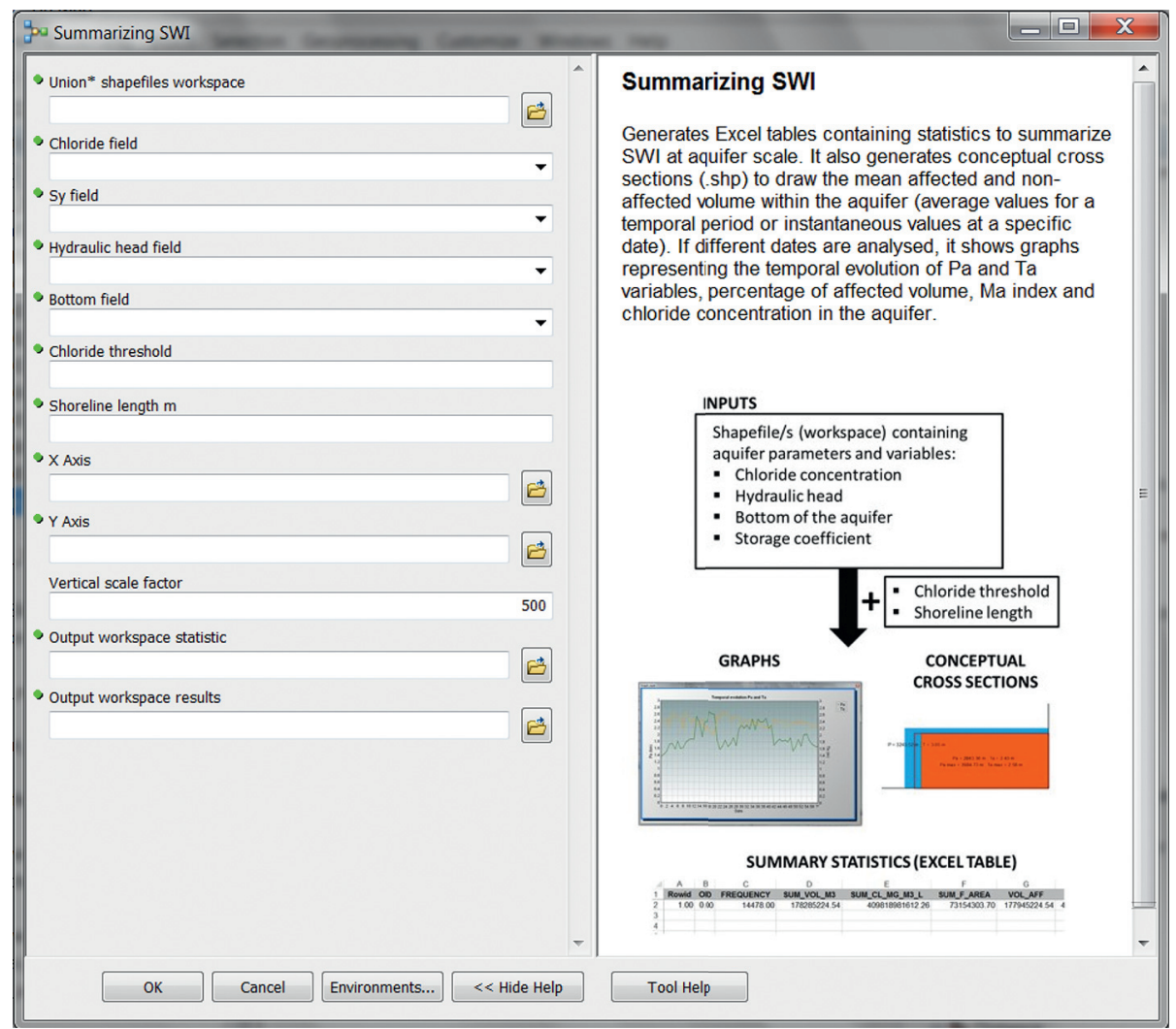

FIgURE 8: Dialog box of the "Summarizing SWI" model. 


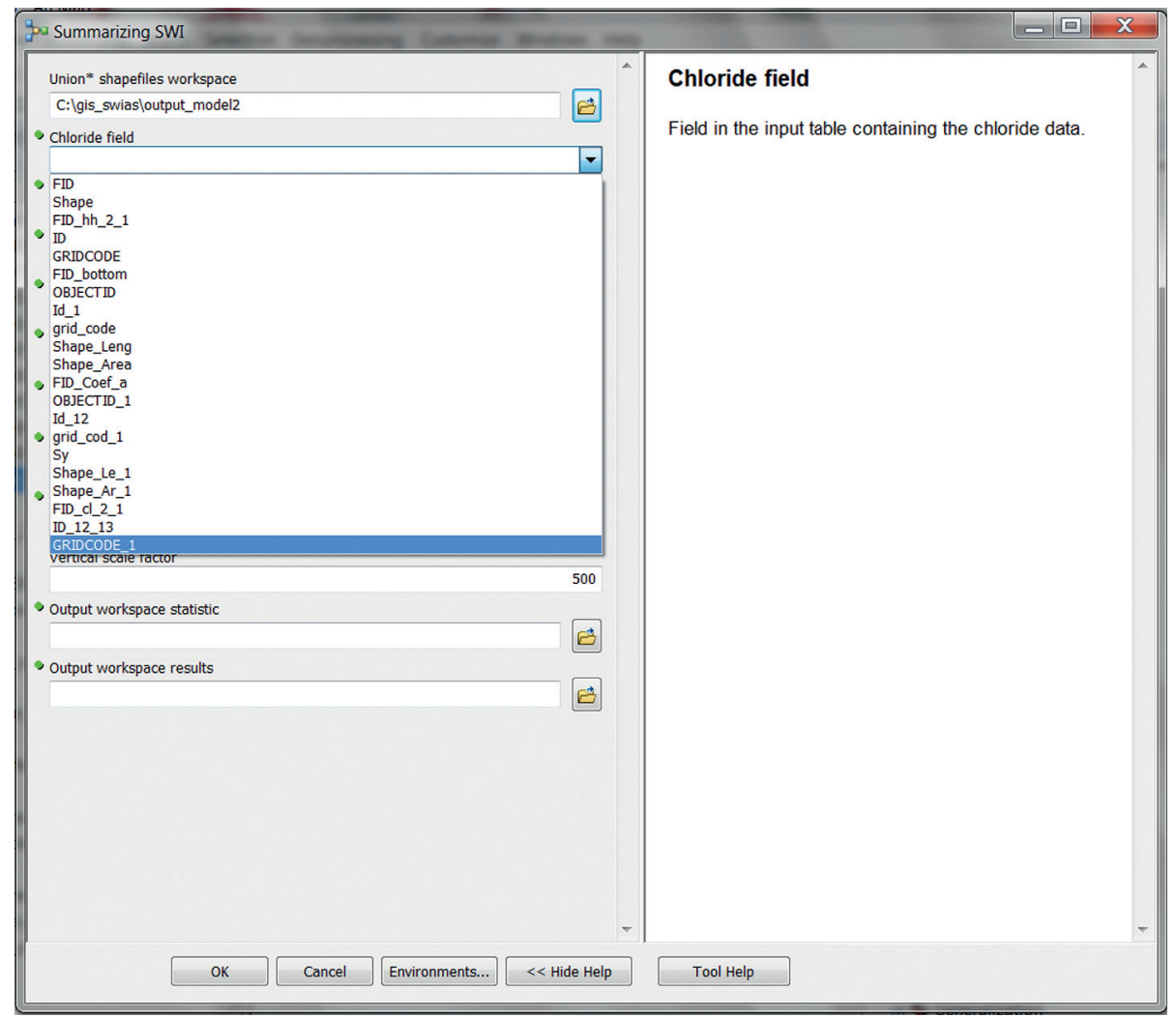

FIGURE 9: Selection of chloride field from the input table.

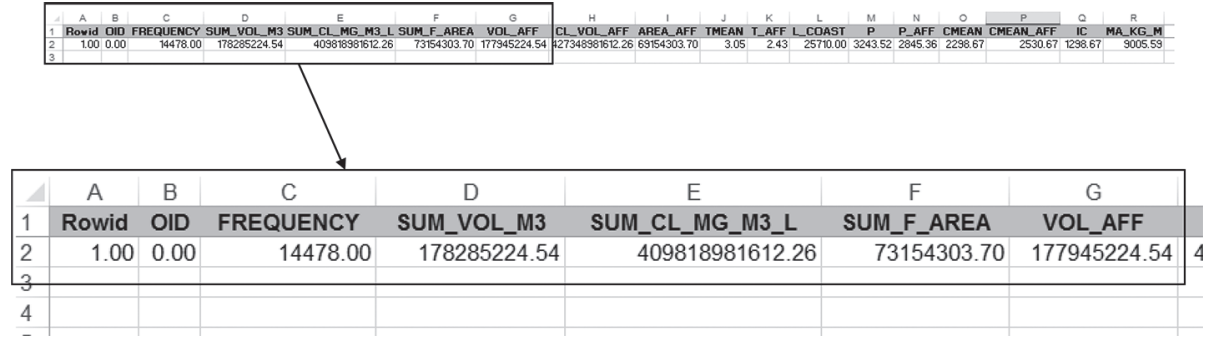

FIgURE 10: Summary statistics for a date.

this case, instead of the chloride concentration maps, generated by executing the "Chloride concentration map" model, polygon shapefiles of the vulnerability index (previously prepared by the user) would be used as inputs of the model "Summarizing SWI vulnerability" (Figure 12), which also will require the "Hydraulic head map" shapefile generated by the tool, as previously described.

The vulnerability index maps must be included as numerical fields (values obtained before defining the vulnerability classes). In order to generate the conceptual cross sections that summarize the "affected" aquifer volume, i.e., where the vulnerability to SWI is identified, the tool requires a vulnerability threshold to be input that represents the reference value chosen to distinguish between affected and nonaffected volumes. This threshold will be also used to assess the lumped vulnerability index.

Just as in the definition of the Ma index, the lumped global value of vulnerability in the aquifer on a specific date is obtained by weighting the vulnerability score in each cell with its water storage. This lumped index also allows an analysis of the dynamic of SWI vulnerability of the system at aquifer scale to be performed. The lumped index can be also obtained using different threshold values $[13,15]$.

\section{Discussion}

GIS-SWIAS is a user-friendly polyvalent ArcGIS tool that provides a comprehensive overview of SWI status and vulnerability at aquifer scale. It integrates three models, which are documented in order to briefly explain the tool's description, its utility, and the data required for each item. This tool can be applied by scientists and decision makers, who may not be advanced users of GIS, to summarize SWI problems. Many GIS-based tools have demonstrated to be powerful and cost-effective to analyze groundwater issues (Criollo et al. and Perdikaki et al. [19, 32]). Moreover, GIS 

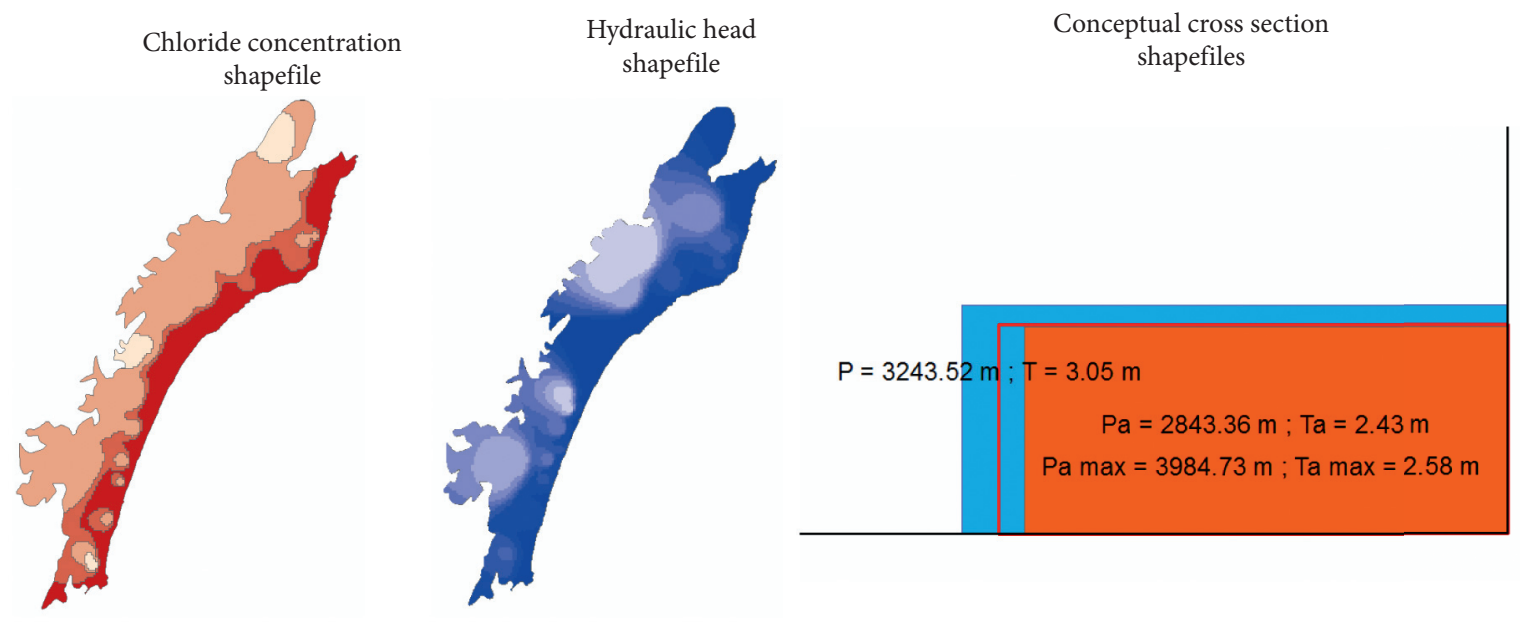

Time series of $\mathrm{Pa}$ and $\mathrm{Ta}$

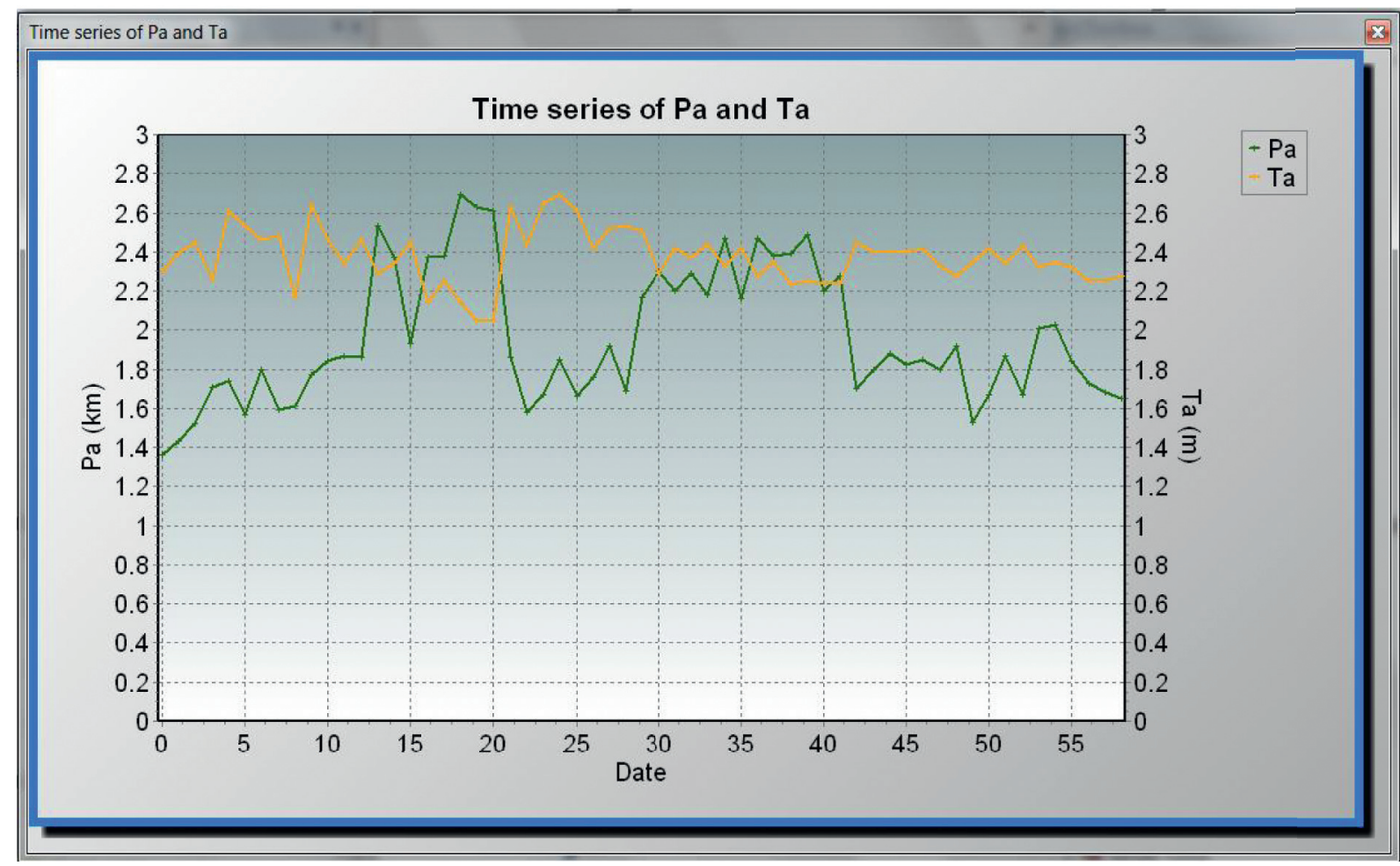

FIgURE 11: Graphical output from the GIS-SWIAS tool.

models as ModelBuilder models can be integrated into other platforms by using the Python script tool (Menezes and Inyang [33]).

Due to the heterogeneous distribution of seawater intrusion, distributed information and assessments are required to study its impacts [8,30]. For this reason, the methods for modelling $[34,35]$ SWI impacts and the userfriendly tools developed based on them [36-38] also require distributed inputs and calculations. The GIS-SWIAS is a tool that could be classified as a postprocessing tool to summarize and help in the analysis of SWI impacts at aquifer scale. This tool produces both distributed and lumped results at aquifer scale, but, logically, it also requires distributed inputs and assessments, as described in the previous sections. In this group of postprocessing tools, we find in the literature, for example, [39]. GIS-SWIAS is a new tool, in which the method proposed by $[13,15]$ has been implemented. A significant novelty of this method with respect to other previously developed methods is that the proposed lumped index to summarize SWI status at aquifer scale is based on a variable with physical meaning (mass of chloride that causes the concentration in some areas to exceed the natural threshold). On the other hand, a novel aspect of this tool is that, from the distributed information and calculations, GISSWIAS allows easy computation of the affected volume containing a chloride concentration above a threshold. This 
TABLE 1: Lumped variables output (Excel ${ }^{\circledR}$ table format) from the GIS-SWIAS tool.

Lumped variables (Excel table)

At a specific moment in time

Total aquifer volume

Total aquifer affected volume

Total chloride concentration $*$ aquifer volume

Total chloride concentration $*$ aquifer volume in the affected volume

Total aquifer area

Total aquifer affected area

Shoreline length

Average aquifer thickness

Average affected aquifer thickness

Average orthogonal distance of the aquifer to the shoreline

Average orthogonal distance of the affected aquifer to the shoreline

Average chloride concentration within the aquifer

Average chloride concentration within the affected volume

Increment of chloride concentration above the threshold value

Ma index

Percentage of affected volume
Statistics for a time period

Average aquifer volume

Average aquifer affected volume

Average chloride concentration $*$ aquifer volume

Average chloride concentration $*$ aquifer volume in the affected volume

Average aquifer area

Average aquifer affected area

Shoreline length

Average aquifer thickness within the period

Average affected aquifer thickness within the period

Average orthogonal distance of the aquifer to the shoreline within the period

Average orthogonal distance of the affected aquifer to the shoreline within the period

Average chloride concentration within the aquifer within the period

Average chloride concentration within the affected volume within the period

Increment of chloride concentration above the threshold value within the period

Average Ma index within the period

Average percentage of affected volume within the period

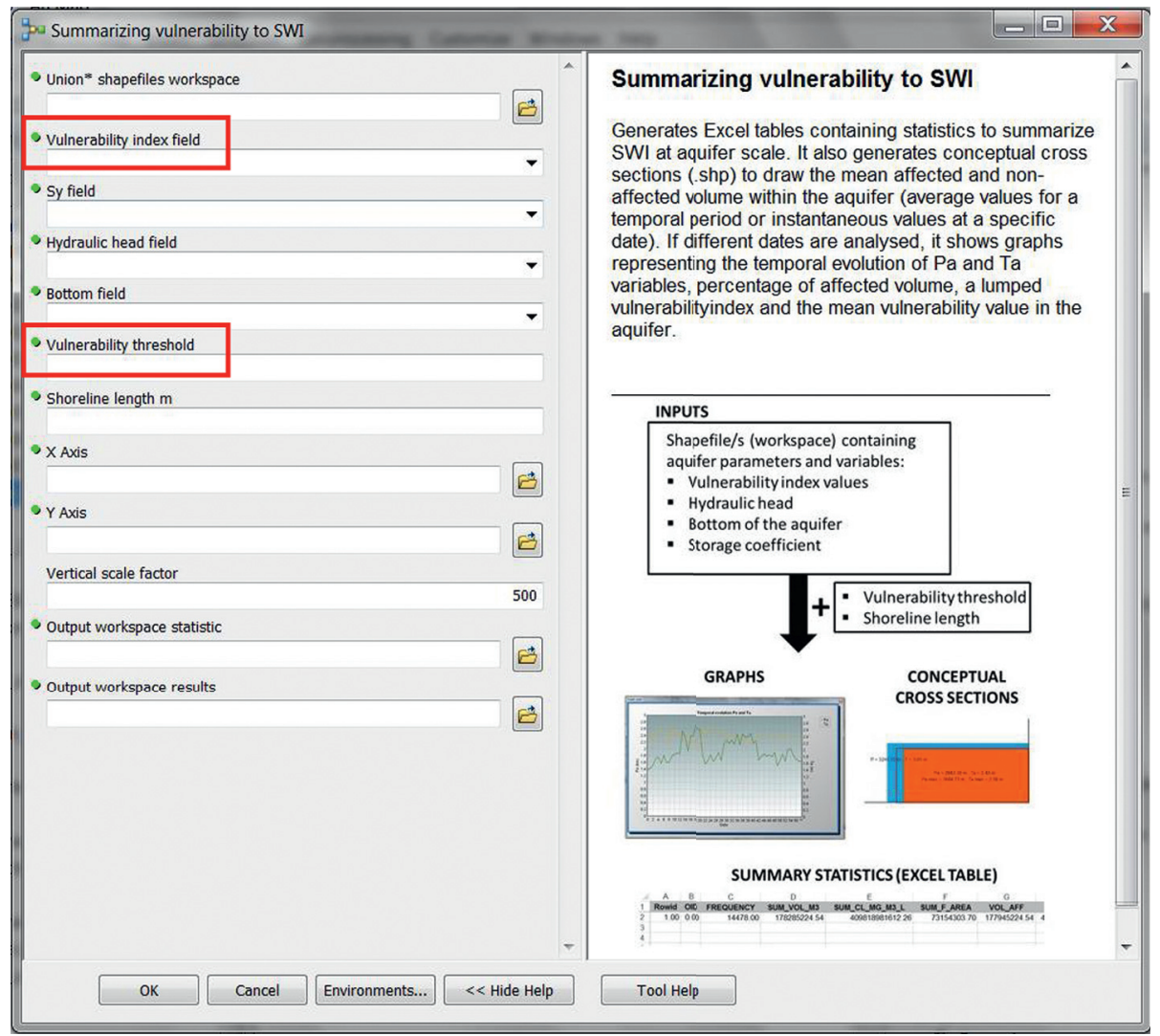

FIgURE 12: Dialog box of the "Summarizing SWI vulnerability" model.

tool also helps to produce lumped SWI outputs (indices) at aquifer scale. It produces valuable information that helps draw conclusions about the dynamic at aquifer scale, in terms of affected volume and global SWI intensity. Thus, it also provides insight into aquifer resilience and trends. Therefore, it will help to identify coastal groundwater bodies that require new management strategies to be implemented to achieve a good status. 
The identification of SWI (the phenomenon that we want to analyze) requires a threshold value established that defines the inflection point beyond which the aquifer begins to register an impact. Previous research shows that the impact of SWI is significantly sensitive to the choice of the threshold value adopted [13]. The significant uncertainties around determining these threshold values [14] and the sensitivity of whether the aquifer is reported as being impacted by SWI or not increase the practical interest of the GIS-SWIAS tool: it is capable of performing the extensive calculations required to summarize SWI at aquifer scale, for the analyses of both historical and potential scenarios, considering different threshold values, which allow the comparison of the results.

With respect to the maps employed as inputs, the tool allows two options: to generate maps from available data using different interpolation techniques integrated in the tool and to take the maps directly from SEAWAT files. This functionality-which allows maps to be generated from point data or to be loaded from other commonly employed tools-has also been implemented in other SWI assessment tools $[36,37]$. However, as far as we know, it is not available in postprocessing tools. In cases where map inputs are taken from density-dependent models, a comparative assessment of different scenarios (climatic conditions and/ or management strategies) could be performed. The physical-process approach can be applied to propagate and compare various potential conditions, and so in this case maps can be obtained and compared for different scenarios (e.g., management scenarios or future potential CC scenarios); this means that the output of the tool can support the decisionmaking process [15]. In contrast, when the maps employed to define the indices are obtained by applying simple interpolation approaches, analysis is limited to the historical period for which the data are available.

The tool also helps to analyze the vulnerability to seawater intrusion at aquifer scale. In the literature, we find different methods to assess groundwater vulnerability depending on the drivers of pollution (Aller et al., Vias et al., and Baena-Ruiz and Pulido-Velazquez [40-42]), pumping (Pulido-Velazquez et al. [43, 44]), and SWI [12, 16]. Userfriendly tools have appeared to assist in this assessment; some of them were developed in a GIS environment [45]. Nevertheless, there are no tools that help in the assessment of SWI vulnerability with that focus on postprocessing. Therefore, this is the first postprocessing tool described that integrates SWI status and vulnerability assessment, which is very valuable information to help identify the significance of SWI problems in aquifers and potential sustainable solutions.

The GIS-SWIAS tool has been applied to two different case studies in the Mediterranean area of Spain (Plana de Oropesa Torreblanca and Plana de Vinaroz), obtaining the results described in previous papers $[13,15]$. In [13], the process automation to generate the interpolated maps enabled authors to analyze SWI status and vulnerability over an extended time period (1977-2015) and to prove the sensitivity of results to the chloride threshold value (two threshold values were analyzed: $250 \mathrm{mg} / \mathrm{l}$ and $1100 \mathrm{mg} / \mathrm{l}$ ) in Plana de Oropesa-Torreblanca and Plana de Vinaroz aquifers. In [15], the impacts of future GC scenarios were analyzed in Plana de Oropesa-Torreblanca aquifer. The methodology from [13] was adapted to compare six potential future scenarios including adaptation strategies. The historical period came from 1973 to 2010 and the six future scenarios covered the period 2011-2035.

The underlying methodology implemented in GISSWIAS was applied in [13] by interpolating chloride maps and hydraulic head from observation points, whereas the information to generate the field maps in [15] was loaded from SEAWAT model. The results of these studies for the Plana de Oropesa-Torreblanca aquifer show differences that reveal that the physical-process SWI approximations obtained using the density-dependent flow model give a more accurate representation. Despite these differences, the results are in the same order of magnitude. Other authors who have developed indices related to SWI $[6,9]$ have also proved that results do not differ considerably by including three-dimensional salinity data. Furthermore, the approximation obtained using interpolation will depend on the number of observations and the distribution of these points within the aquifer.

Although this tool has been developed to analyze SWI problem, it could be applied to study the lumped impact of any contaminant on groundwater and/or the groundwater vulnerability by applying any vulnerability index. In this case, instead of the "Shoreline length" parameter to generate the cross section, other equivalent lengths (e.g., the aquifer length orthogonal to the groundwater flow direction) should be considered. Therefore, GIS-SWIAS fulfils the requirements of flexibility, sturdiness, easy interaction, and userfriendliness, which make it a useful tool in the decisionmaking process. It will allow using them as "share vision models/tools" to help in the discussion of management alternatives between stakeholders and administration representatives [46]. Many Decision Support Systems tools were not successful because they were not user-friendly $[47,48]$.

4.1. Assumptions and Limitations. In this section we summarize the main assumptions/limitations of the GIS-SWIAS tool and in the implemented methodology.

\subsubsection{Underlying Methodology.}

(i) The methodology implemented [13] provides lumped results at aquifer scale. An analysis based exclusively on these lumped results would lose information about the heterogeneity of SWI in the system.

(ii) Although the method can be applied in cases where a distributed flow model is not available, a proper assessment for a specific date requires sufficient distributed data about hydraulic head, chloride concentration, and aquifer bottom. On the other hand, to generate the required fields from the data, it needs to apply an interpolation approach whose parameters influence on the results. It is recommended that the user tests different interpolation 
approaches and parameters in order to obtain results in agreement with expert opinion.

(iii) In order to assess the dynamic of SWI and the resilience of the aquifer, there is need to have data for several dates over a long period.

(iv) If the aim is to assess sustainable management strategies, appropriate hydrological models to propagate the impacts are required, not only of the climatic conditions, but also of the management strategies.

\subsubsection{GIS-SWIAS Tool.}

(i) This tool has been implemented in ArcGIS and is licensed GIS software. Future implementations may be developed in an open environment.

(ii) The GIS-SWIAS tool had to be divided into three models due to some difficulties that arose to implement all the geoprocesses into one model. Nevertheless, in the future, we plan to combine these three steps into one, improving the usability of the model.

(iii) Graphic results are based on a predefined template. Although graphs in ArcGIS are customizable, there is not so much potential.

(iv) Output reports are generated automatically in Excel format and lack a refined style.

\section{Conclusions}

In this paper we describe a new general tool, GIS-SWIAS. It is an ArcGIS-based tool, designed to analyze SWI status and vulnerability at aquifer scale by applying the method presented by $[13,15]$. It is a user-friendly tool that allows georeferenced information to be dealt with, and it is easy to introduce the required data (inputs) and to efficiently perform the demanding computational operations required. Its outputs are in the form of reports and images to summarize the magnitude, intensity, and temporal evolution of SWI within an aquifer.

The GIS-SWIAS tool can be applied to assess historical SWI dynamic in case studies where we do not have a previous model. Nevertheless, if we want to analyze in a rational quantitative analysis of the various alternative management scenarios to manage SWI in a sustainable manner, the GIS-SWIAS tool will need to take information on hydraulic head and chloride concentration distribution generated from simulations of their impacts by a calibrated density-dependent flow model. In such cases, adaptation strategies to potential future scenarios, whose distributed impacts have to be propagated within the previously calibrated models, could usefully be analyzed and compared using this tool. GIS-SWIAS can be applied to assess not only SWI status at aquifer scale, but also vulnerability to any contaminant.

Given all these ways that the GIS-SWIAS tool can be applied, it provides a valuable tool for both researcher and technician to assess SWI dynamics and aquifer resilience under different management scenarios. It can support the decision-making process in the rational selection of sustainable management strategies. The tool's performance has been tested and confirmed in two case studies described in previous research works.

It can be applied to any case study. The easy-to-use workflow and the few input data required facilitate its application to a large number of case studies in order to compare SWI.

\section{Data Availability}

The software developed in this study may be released upon application to the authors, who can be contacted at 1.baena@ igme.es or d.pulido@igme.es.

\section{Conflicts of Interest}

The authors declare that there are no conflicts of interest regarding the publication of this paper.

\section{Acknowledgments}

This work has been supported by the GeoE.171.008-TACTIC and GeoE.171.008-HOVER projects from GeoERA Organization funded by European Union's Horizon 2020 Research and Innovation Program and SIGLO-AN (RTI2018101397-B-I00) project from the Spanish Ministry of Science, Innovation and Universities (Programa Estatal de $\mathrm{I}+\mathrm{D}+\mathrm{I}$ orientada a los Retos de la Sociedad).

\section{References}

[1] Water Framework Directive (WFD), “Directiva 2000/60/CE del Parlamento Europeo y del Consejo de 23 de Octubre de 2000," Diario Oficial de las Comunidades Europeas de 22/12/ 2000, Water Framework Directive (WFD), L 327/ 1-327/32, 2000.

[2] N. Momejian, M. Abou Najm, I. Alameddine, and M. ElFadel, "Groundwater vulnerability modeling to assess seawater intrusion: a methodological comparison with geospatial interpolation," Water Resources Management, vol. 33, no. 3, pp. 1039-1052, 2019.

[3] V. Elumalai, K. Brindha, B. Sithole, and E. Lakshmanan, "Spatial interpolation methods and geostatistics for mapping groundwater contamination in a coastal area," Environmental Science and Pollution Research, vol. 24, no. 12, pp. 1160111617, 2017.

[4] C. Llopis-Albert and D. Pulido-Velazquez, "Discussion about the validity of sharp-interface models to deal with seawater intrusion in coastal aquifers," Hydrological Processes, vol. 28, no. 10, pp. 3642-3654, 2014.

[5] C. Llopis-Albert and D. Pulido-Velazquez, "Using MODFLOW code to approach transient hydraulic head with a sharp-interface solution," Hydrological Processes, vol. 29, no. 8, pp. 2052-2064, 2015.

[6] A. Renau-Pruñonosa, I. Morell, and D. Pulido-Velazquez, "A methodology to analyse and assess pumping management strategies in coastal aquifers to avoid degradation due to seawater intrusion problems," Water Resources Management, vol. 30, no. 13, pp. 4823-4837, 2016. 
[7] A.-J. Collados-Lara, D. Pulido-Velazquez, and E. PardoIgúzquiza, "An integrated statistical method to generate potential future climate scenarios to analyse droughts," Water, vol. 10, no. 9, pp. 1224-1248, 2018.

[8] D. Pulido-Velazquez, A. Renau-Pruñonosa, C. Llopis-Albert et al., "Integrated assessment of future potential global change scenarios and their hydrological impacts in coastal aquifers - a new tool to analyse management alternatives in the Plana Oropesa-Torreblanca aquifer," Hydrology and Earth System Sciences, vol. 22, no. 5, pp. 3053-3074, 2018.

[9] B. J. Ballesteros, I. Morell, O. García-Menéndez, and A. Renau-Pruñonosa, "A standardized index for assessing seawater intrusion in coastal aquifers: the SITE index," Water Resources Management, vol. 30, no. 13, pp. 4513-4527, 2016.

[10] M. Tomaszkiewicz, M. Abou Najm, and M. El-Fadel, "Development of a groundwater quality index for seawater intrusion in coastal aquifers," Environmental Modelling \& Software, vol. 57, pp. 13-26, 2014.

[11] I. S. Babiker, M. A. A. Mohamed, and T. Hiyama, "Assessing groundwater quality using GIS," Water Resources Management, vol. 21, no. 4, pp. 699-715, 2007.

[12] A. Zeynolabedin and R. Ghiassi, "The SIVI index: a comprehensive approach for investigating seawater intrusion vulnerability for island and coastal aquifers," Environmental Earth Sciences, vol. 78, 2019.

[13] L. Baena-Ruiz, D. Pulido-Velazquez, A.-J. Collados-Lara, A. Renau-Pruñonosa, and I. Morell, "Global assessment of seawater intrusion problems (status and vulnerability)," Water Resources Management, vol. 32, no. 8, pp. 2681-2700, 2018.

[14] K. Hinsby, M. T. Melo, and M. Dahl, "European case studies supporting the derivation of natural background levels and groundwater threshold values for the protection of dependent ecosystems and human health," The Science of the Total Environment, vol. 401, no. 1-3, pp. 1-20, 2008.

[15] L. Baena-Ruiz, D. Pulido-Velazquez, A.-J. Collados-Lara et al., "Summarizing the impacts of future potential global cdslfthange scenarios on seawater intrusion at the aquifer scale," Environmental Earth Sciences, vol. 79, no. 5, p. 99, 2020.

[16] A. G. Chachadi and J. P. Lobo Ferreira, "Assessing aquifer vulnerability to sea-water intrusion using GALDIT method: Part 2-GALDIT indicator descriptions," in Water in Celtic Countries: Quantity, Quality and Climate Variability, J. P. Ferreira, Ed., Proceedings of the fourth interceltic colloquium on hydrology and management of water resources IAHS Press Publications, Guimarães, Portugal, pp. 172-180, 2007.

[17] J. Andreu, J. Capilla, and E. Sanchís, "AQUATOOL, a generalized decision-support system for water-resources planning and operational management," Journal of Hydrology, vol. 177, no. 3-4, pp. 269-291, 1996.

[18] E. Vázquez-Suñé, E. Abarca, J. Carrera et al., "Groundwater modelling as a tool for the European water framework directive (WFD) application: the llobregat case," Physics and Chemistry of the Earth, Parts $A / B / C$, vol. 31, no. 17, pp. 1015-1029, 2006.

[19] R. Criollo, V. Velasco, A. Nardi et al., "AkvaGIS: an open source tool for water quantity and quality management," Computers \& Geosciences, vol. 127, pp. 123-132, 2019.

[20] D. Machiwal, M. K. Jha, V. P. Singh, and C. Mohan, "Assessment and mapping of groundwater vulnerability to pollution: current status and challenges," Earth-Science Reviews, vol. 185, pp. 901-927, 2018.
[21] A. Rikalovic, I. Cosic, and D. Lazarevic, "GIS based multicriteria analysis for industrial site selection," Procedia Engineering, vol. 69, no. 12, pp. 1054-1063, 2014.

[22] D. Machiwal and M. K. Jha, "Role of geographical information system for water quality evaluation," in Geographic Information Systems (GIS): Techniques, Applications and Technologies, D. Nielson, Ed., pp. 217-278, Nova Science Publishers, New York, NY, USA, 2014.

[23] W. Gossel, A. M. Ebraheem, and P. Wycisk, "A very large scale GIS-based groundwater flow model for the Nubian sandstone aquifer in Eastern Sahara (Egypt, northern Sudan and eastern Libya)," Hydrogeology Journal, vol. 12, no. 6, pp. 698-713, 2004.

[24] L. Wang, C. R. Jackson, M. Pachocka, and A. Kingdon, "A seamlessly coupled GIS and distributed groundwater flow model," Environmental Modelling \& Software, vol. 82, pp. 1-6, 2016.

[25] M. Alcaraz, E. Vázquez-Suñé, V. Velasco, and R. Criollo, “A loosely coupled GIS and hydrogeological modeling framework," Environmental Earth Sciences, vol. 76, no. 11, p. 382, 2017.

[26] G. Bhatt, M. Kumar, and C. J. Duffy, "A tightly coupled GIS and distributed hydrologic modeling framework," Environmental Modelling \& Software, vol. 62, pp. 70-84, 2014.

[27] C. N. Almeida, J. Roehrig, and E. Wendland, "Development and integration of a groundwater simulation model to an open geographic information system," JAWRA-Journal of the American Water Resources Association, vol. 50, no. 1, pp. 101-110, 2014.

[28] T. A. Akbar, H. Lin, and J. DeGroote, "Development and evaluation of GIS-based ArcPRZM-3 system for spatial modeling of groundwater vulnerability to pesticide contamination," Computers \& Geosciences, vol. 37, no. 7, pp. 822-830, 2011.

[29] J. F. Rios, M. Ye, L. Wang, P. Z. Lee, H. Davis, and R. Hicks, "ArcNLET: a GIS-based software to simulate groundwater nitrate load from septic systems to surface water bodies," Computers \& Geosciences, vol. 52, pp. 108-116, 2013.

[30] R. Ali, D. McFarlane, S. Varma, W. Dawes, I. Emelyanova, and G. Hodgson, "Potential climate change impacts on the water balance of regional unconfined aquifer systems in southwestern Australia," Hydrology and Earth System Sciences, vol. 16, no. 12, pp. 4581-4601, 2012.

[31] G. De Filippis, C. Pouliaris, D. Kahuda et al., "Spatial data management and numerical modelling: demonstrating the application of the QGIS-integrated FREEWAT platform at 13 case studies for tackling groundwater resource management," Water, vol. 12, no. 1, p. 41, 2020.

[32] M. Perdikaki, R. C. Manjarrez, C. Pouliaris, R. Rossetto, and A. Kallioras, "Free and open-source GIS-integrated hydrogeological analysis tool: an application for coastal aquifer systems," Environmental Earth Sciences, vol. 79, no. 14, p. 348, 2020.

[33] G. B. Menezes and H. I. Inyang, "GIS-based contaminant transport model for heterogeneous hydrogeological settings," Journal of Environmental Informatics, vol. 14, no. 1, 2009.

[34] M. G. McDonald and A. W. Harbaugh, "A modular threedimensional finite-difference ground-water flow model," U.S. Geological Survey Techniques of Water-Resources Investigations, Washington, DC, USA, 1988, p. 586, book 6, chap. A1.

[35] M. Bakker, F. Schaars, J. D. Hughes, C. D. Langevin, and A. M. Dausman, "Documentation of the seawater intrusion (SWI2) package for MODFLOW," U.S. Geological survey 
techniques and methods, Washington, DC, USA, 2013, p. 47, book 6, chap. A46, https://pubs.usgs.gov/tm/6a46/.

[36] Waterloo Hydrogeologic Inc., Visual MODFLOW User's Manual, Waterloo Hydrogeologic. Inc., Waterloo, Canada, 2005.

[37] W. H. Chiang and W. Kinzelbach, 3D-Groundwater Modeling with PMWIN: A Simulation System for Modeling Groundwater Flow and Transport Processes, vol. 2, Springer, New York, NY, USA, 2001.

[38] R. B. Winston, ModelMuse: A Graphical User Interface for MODFLOW-2005 and PHAST, p. 52, US Geological Survey, Reston, VA, USA, 2009.

[39] R. Criollo, V. Velasco, E. Vázquez-Suñé, A. Serrano-Juan, M. Alcaraz, and A. García-Gil, "An integrated GIS-based tool for aquifer test analysis," Environmental Earth Sciences, vol. 75 , no. 5 , p. 391, 2016.

[40] L. Aller, T. Bennett, J. Lehr, R. Petty, and G. Hackett, DRASTIC: A Standardized System for Evaluating Groundwater Pollution Potential Using Hydrogeologic Settings, U.S. Environmental Protection Agency, p. 622, Washington, DC, USA, 1987.

[41] J. M. Vías, B. Andreo, M. J. Perles, F. Carrasco, I. Vadillo, and P. Jiménez, "Proposed method for groundwater vulnerability mapping in carbonate (karstic) aquifers: the COP method," Hydrogeology Journal, vol. 14, no. 6, pp. 912-925, 2006.

[42] L. Baena-Ruiz and D. Pulido-Velazquez, "A novel approach to harmonize vulnerability assessment in carbonate and detrital aquifers at basin scale," Water, vol. 12, no. 11, p. 2971, 2020.

[43] D. Pulido-Velazquez, A.-J. Collados-Lara, L. Baena-Ruiz, F. Fernández-Chacón, and F. J. Alcalá, Assessment of Present and Future Vulnerability to Pumping in Spanish Groundwater Bodies Using a Natural Turnover Time Index, IAH, Dubrovnik, Croatia, 2017.

[44] D. Pulido-Velazquez, J. Romero, A.-J. Collados-Lara, F. J. Alcalá, F. Fernández-Chacón, and L. Baena-Ruiz, "Using the turnover time index to identify potential strategic groundwater resources to manage droughts within continental Spain," Water, vol. 12, no. 11, p. 3281, 2020.

[45] L. Duarte, A. C. Teodoro, J. A. Gonçalves, A. J. Guerner Dias, and J. E. Marques, "Assessing groundwater vulnerability to pollution through the DRASTIC method," in Proceedings of the International Conference on Computational Science and its Applications, pp. 386-400, Minho, Guimaraes, Portugal, July 2014.

[46] D. P. Loucks and E. Van Beek, Water Resource Systems Planning and Management: An Introduction to Methods, Models, and Applications, Springer, Berlin, Germany, 2017.

[47] R. F. Reitsma, "Structure and support of water-resources management and decision-making," Journal of Hydrology, vol. 177, no. 3-4, pp. 253-268, 1996.

[48] M. T. Atta, "The effect of usability and information quality on decision support information system (DSS)," Arts and Social Sciences Journal, vol. 8, no. 2, p. 257, 2017. 